\title{
Bacteriochlorophyll aggregates in positively charged micelles
}

\author{
J. Gottstein ${ }^{a}$, A. Scherz ${ }^{b}$ and H. Scheer ${ }^{\mathrm{a}, *}$ \\ ${ }^{a}$ Botanisches Institut der Universität München, D-80638 München (Germany) and ${ }^{b}$ Biochemistry Department, \\ The Weizmann Institute, Rehovot (Israel)
}

(Received 12 October 1993)

Key words: Photosynthesis; Chlorophyll; Micelle; Aggregation; Self-organization; Detergent action

Micellar complexes were prepared from bacteriochlorophyll $a$ and bacteriopheophytin $a$ with the cationic detergents, cetyltrimethyl ammonium bromide and cetylpyridinium chloride. These complexes have spectroscopic properties (absorption, circular dichroism) which are very different from the ones formed with non-ionic detergents like Triton X-100, and also with anionic detergents. Bacteriochlorophyll $a$ forms two complexes: One is blue-shifted and has excitonically coupled $\mathrm{Q}_{y}$ transitions. The second one is extremely red-shifted. The unusual properties are suggested to result from interactions of the positively charged head-group of the detergent with the tetrapyrrole.

\section{Introduction}

Many of the spectral properties of photosynthetic systems have been related to interactions among closely spaced chlorophylls [1-18]. The aggregation of these pigments has, therefore, received much attention in the past. The 'classical' aggregates observed in, for example, organic solvents $[2,3,6,18]$ involve the interaction of electron-donating peripheral carbonyl groups, and the electron-accepting central magnesium atom. They interact either directly or - if present - via multifunctional ligands like water, dioxan, etc. A new type of chlorophyll aggregation has recently been proposed from studies on chlorophyll in micelles [4,5,9-16]. This micellar aggregation is due mainly to interaction of the $\pi$-systems producing aggregates in which the tetrapyrroles are nearly parallel, and generally occurs irrespective of the absence and presence of the central magnesium.

The spectra of these complexes are generally characterized by large red shifts, excitonic coupling, and hyperchromism of the red $\left(Q_{y}\right)$ band. These properties and also the structures suggested, are strikingly similar to components of the photosynthetic reaction centers for which the three-dimensional structures are known [19-26]. This suggests (i) that formation of such structures is an inherent property of the chromophores, and

\footnotetext{
* Corresponding author. Fax: +4989 1782274.

Abbreviations: Chl $a$, chlorophyll $a$; BChl $a$, bacteriochlorophyll $a$; BPhe $a$, Bacteriopheophytin $a$; CTAB, cetyltrimethyl ammonium bromide; CPC, cetylpyridinium chloride; T-X100, Triton X-100.
}

(ii) that it may hence be a structural factor in (bacterio)chlorophyll proteins. Furthermore, the large spectral changes indicate, that (iii) structural variations of the micelle and the protein matrix can be monitored by these pigments in a sensitive way.

In a systematic study of the self-organization of chlorophyllous pigments in micellar environment, we have now screened a variety of detergents. Previous results with chlorophyll $a(\mathrm{Chl} a)$ indicated that complexes like the ones in Triton X-100 (TX-100) are formed in all detergents except those with positively charged head-groups [11,12]. With the latter, blueshifted complexes were formed instead. These studies have now been extended to bacteriochlorophyll $a$ (BChl a) and its demetalated derivative, bacteriopheophytin $a$ (BPhe $a$ ). In all cases investigated, cationic detergents form complexes which exhibit (i) more or less pronounced blue-shifts of both the $Q_{y}$ transition and the Soret band, (ii) strong hypochromism of the $Q_{y}$ band and (iii) a concomitant hypochromism of the Soret band. A second, extremely red-shifted complex is formed with bacteriochlorophyll $a$ and cetyltrimethyl ammonium bromide (CTAB), which may be the first experimental observation of the effect of peripheral positive charges on (B)Chl, which has been proposed on theoretical grounds [27-31].

$\mathrm{BChl} a$ was prepared from Rhodobacter spheroides R26, as reported before $[9,15]$. Pheophytinization was carried out with formic acid, which was added dropwise to an etheral solution of BChl $a$ until a stable color-change was obtained. All detergents were purchased from Sigma (München) and used without fur- 
ther purification. For the preparation of the complexes, the desired amount of the pigment dissolved in diethylether, was evaporated by a stream of nitrogen in a test tube, and the residual film solubilized in the aqueous detergent by sonication (Branson, model 52). The process was followed spectrophotometrically and usually continued until no further changes in the optical absorption of the sample were observed. Absorption and circular dichroism spectra were recorded with a Lambda 2 (Perkin-Elmer, Überlingen) spectrophotometer and Dichograph VI (Jobin-Yvon, France) spectropolarimeter, respectively.

$\mathrm{BChl} a$ forms two types of complex upon sonication with cationic detergents: an initial complex is formed at short sonication times with both CTAB and cetylpyridinium chloride (CPC). It differs from monomeric BChl $a$ mainly by a broadening of the $\mathrm{Q}_{y}$ band. This complex transforms at longer sonication times into a second type (Fig. 1). The broadened and structured $Q_{y}$ band of the initial complex shows that it is heterogeneous, and has many characteristics of $\mathrm{BChl}$ $a$ in monomeric solution e.g. in polar organic solvents. In the CTAB micelle, the centers of the double-peaked red $\left(\mathrm{Q}_{y}\right)$ band $\left(\lambda_{\max }=761\right.$ and $\left.789 \mathrm{~nm}\right)$ is only slightly blue-shifted as compared to the monomer $\left(\lambda_{\max }=780\right.$ $\mathrm{nm})$. The visible $\left(\mathrm{Q}_{x}\right)$ band is blue-shifted by $\approx 25 \mathrm{~nm}$ $\left(\lambda_{\max }=573 \mathrm{~nm}\right)$, a position characteristic for singly ligated BChl $a$ [32]. The intensity of the $\mathrm{Q}_{y}$ transition is strongly attenuated relative to the Soret band, while $\mathrm{Q}_{x}$ retains its intensity, as compared to monomeric

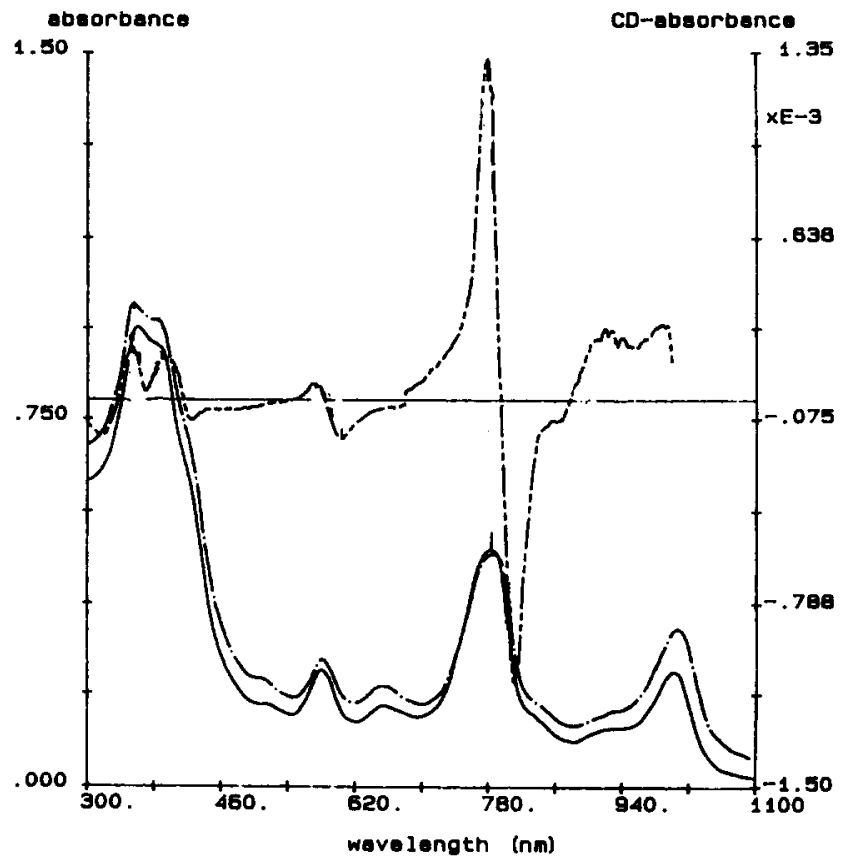

Fig. 1. Absorption (bottom) and CD spectra (top) of BChl $a$ in micellar solution of CTAB $(0.1 \%)$ in water. The deposited pigment was sonified for $1(\longrightarrow)$ and $3 \mathrm{~h}(\cdots,-)$. The $C D$ spectrum $(\cdots, \ldots)$ was taken after $3 \mathrm{~h}$ of sonification.

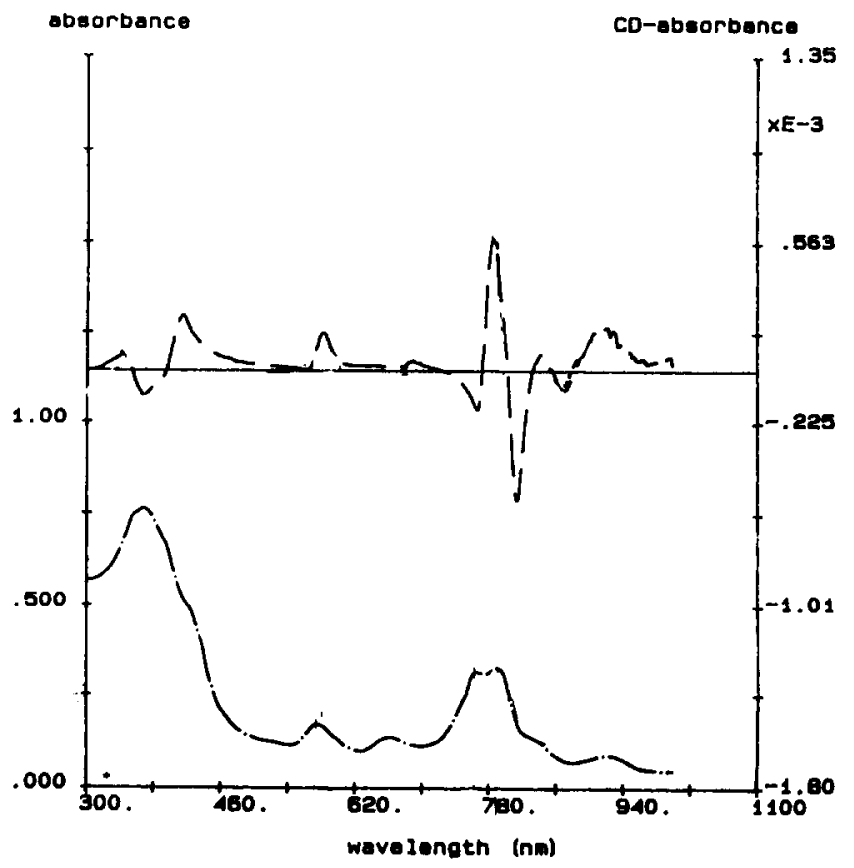

Fig. 2. Absorption (bottom) and $\mathrm{CD}$ spectra (top) of $\mathrm{BChl} a$ in micellar solution of cetyl-pyridiniumchloride (CPC) $(0.1 \%)$ in water. The deposited pigment was sonified for $1 \mathrm{~h}$.

$\mathrm{BChl} a$. Both features are in contrast to the aggregates formed in, for example, TX-100, which show a large red shift, pronounced hyperchromism of the $\mathrm{Q}_{y}$ band, pronounced hypochromism of the $\mathrm{Q}_{x}$ and (to a lesser extent) the Soret bands. This initial complex is nonetheless aggregated if judged from circular dichroism. An S-shaped, conservative CD-feature is related to each absorption band. One of the $\mathrm{Q}_{y}$ bands (at 789 $\mathrm{nm}$ ) is centered at the long wavelength side of the monomeric absorption band, and its anisotropy ( $\Delta A$ $\approx 2 \cdot 10^{-3}$ ) is intermediate between the intense one observed for TX-100 complexes, and the low anisotropy of BChl $a$ in monomeric solution [9].

In CPC micelles, the absorption spectra are principally similar. However, the $Q_{y}$ band is more structured and clearly reveals the presence of two bands of similar intensity (Fig. 2). The related $\mathrm{CD}$ feature is more complex, and can be most readily explained by two excitonic couplets of opposite order, which are centered close to the two absorption maxima. Again, the $C D$ of both the Soret and the $Q_{x}$ bands show distinct features. It is therefore concluded, that these complex(es) are aggregates, or a mixture of aggregated forms, each showing excitonic interaction.

In the CTAB micelle, an extremely red-shifted band $\left(\lambda_{\max }=1005 \mathrm{~nm}\right)$ is already present in the spectrum at early times, but growing progressively upon continuing sonication (Fig. 1). With the rise of this band, the $Q_{y}$ band loses intensity, the $Q_{x}$ band slightly shifts to the red, and a red shoulder of the Soret band intensifies. The $\mathrm{Q}_{x}$ and Soret bands related to this complex are 
not as well separated, but their intensities and locations can be estimated from the difference obtained from the two spectra [14].

Compared to monomeric solution, the red-shift of the $\mathrm{Q}_{y}$ band of this complex amounts to $2870 \mathrm{~cm}^{-1}$, which is to our knowledge the largest observed for any $\mathrm{BChl} a$ system. Red shifts of BChl $a$-protein complexes range between 320 (B800 antennas) [33,34] and $1650 \mathrm{~cm}^{-1}$ (B895) [35], those of BChl $a$ complexes in TX-100 or the like were maximally shifted by 2000 $\mathrm{cm}^{-1}[1,9,14]$. A red-shift of comparable size $(\leq 2550$ $\mathrm{cm}^{-1}$ ) is observed in the antenna and in the primary donor of BChl-b-containing reaction center of Rhodopseudomonas viridis $[33,35,36]$. Although the structures of the two BChl's and also the arrangements of the primary donors in reaction centers of the BChl- $a$ containing Rhodobacter spheroides and BChl-b-containing $R p$. viridis are very similar $[23,25]$, the larger redshift in the latter is probably related to environmental effects of the protein and structural differences of the pigments, but its exact origin is still unclear.

One factor, which has been explored by several groups, is the effect of positive charges located at the periphery of the tetrapyrrole macrocycle [27-31]. However, there has been little supporting experimental evidence $[29,31]$. It is rather intriguing that the cationic detergent with a 'hard' positive charge, e.g. CTAB, produces the extreme red-shift observed with the $\mathrm{BChl}$ $a$ complex of the second type. Its absence in CPC may be related to the more delocalized positive charge, but also to another location of the charge in the micelle.

BPhe a forms a complex with a considerably broadened $Q_{y}$ band, which extends towards longer wavelengths, but is generally only poorly structured (not shown). A similar type of spectrum has been obtained with Chl $a$ in TX-100 [12]. Another distinct feature is the rather large intensity of the $Q_{x}$ band, which is reminescent of the hypochromism of this band (and the concomitant pronounced hyperchromism of the $\mathrm{Q}_{y}$ band), in complexes of $\mathrm{Chl} a$ with cationic detergents [12]. Thus, the rule holds again that blue-shifting of the $\mathrm{Q}_{y}$ band goes along with a decrease of its intensity. With BPhe $a$, there is no obvious equivalent to the extremely red-shifted type II complex. However, the long-wavelength tail of the $Q_{y}$ band is sometimes structured and reveals distinct red-shifted components up to $852 \mathrm{~nm}$, which is close to the one observed for the BPhe $a$ aggregates in non-ionic detergents like TX-100. It is possible, that the BPhe $a$ complexes are more heterogeneous, and that the effect of a positive charge is less pronounced in the $\mathrm{Mg}$-free pigments.

Interactions among the individual chromophores in $\mathrm{BChl}$ dimers and larger aggregates are now believed to the major mechanism by which their long wavelength transitions are shifted in vivo (see, for example, Refs. 5,14). Yet, several theoretical studies have predicted that, under some circumstances, the protein matrix, too, may significantly alter the spectra of the indicidual pigments. In particular, negative or positive charges located near the carbonyl residues of the $\mathrm{BChls}$ were suggested to be of profound effect [27-31]. However, there is only a single experimental study in which a positive charge has been placed close to ring II of chlorophyll $a$ and thereby produces only a small shift [29], and so far there is no documented case for having charged residues near the pigments in BChl-proteins [19-26,31]. However, transient localization of charges occurs during the primary steps of photosynthesis, possibly subjecting each pigment at a time to the aforementioned interaction.

It is difficult to test this idea by exploring the in vivo pigments, mainly because introduction of charged residues to the hydrophobic surrounding of the $\mathrm{BChl}$ or BPhe may alter the protein structure. The aggregation of the photosynthetic pigments in micelles has been recently proved as a valuable alternative tool for elucidating the mechanisms governing the spectral properties of the $\mathrm{BChl}$ and $\mathrm{Chl}$, and to mimic the in vivo situation (for a recent review see Ref. 14). Here, we employ similar techniques to study the charge effect on the pigments' absorption by using cationic detergents.

The solubilized pigments have their oscillator strength in the $Q_{y}$ region strongly attenuated relative to that of the Soret bands. Similar phenomena were recently observed in complexes of Chl $a$, Phe $a$ or $\mathrm{BChl} a$ with several aromatic compounds, and interpreted in terms of ground state electron delocalization from the Chls to the aromatics (Ref. 37; Fiedor, L., Brumfeld, V. and Scherz, A., unpublished results, 1993). We propose that, in the present case, there is a partial charge delocalization from BChl $a$ to the positive head-groups of the CTAB molecules causing the attenuation of the $Q_{y}$ transition. The positive headgroups of CTAB may also impose electrostatic interactions with the $\mathrm{BChl} a$ [30].

Following this assumption we shall proceed to a more detailed interpretation of the spectra. The BChl $a$ makes two spectroscopic forms in the positively charged CTAB micelles (Fig. 1). One form has the optical absorption of monoligated BChl $a$ monomers with $\mathrm{Q}_{y}$ and $\mathrm{Q}_{x}$ absorption maxima at 780 and $580 \mathrm{~nm}$, respectively [32]. However, the concomitant intense, double banded $\mathrm{CD}$ is indicative of exciton splitting due to interactions among the transition dipoles of weakly coupled molecules. The signals are strictly doublets, meaning that the interaction is limited (mainly) to two molecules per micelle.

In the other spectral form of $\mathrm{BChl} a$ the $\mathrm{Q}_{y}$ transition is shifted to $1010 \mathrm{~nm}$. This absorption seemed to be accompanied by a weak CD signal, if judged from the spectrum up to the limits $(1000 \mathrm{~nm})$ of the spec- 
trometer used. We suggest, that the long wavelength transition is due to self-assembled dimers of the BChl $a$ molecules within the CTAB micelles, whose absorptions are strongly shifted by the positively charged head-groups.

Assuming that CTAB forms spherical or tubular micelles (thereby minimizing the repulsion between the positive head-groups) of $>100$ molecules each, taking into account the critical micelle concentration $\left(28 \cdot 10^{-3}\right.$ $M[11])$ of $C T A B$ and the pigment concentration $(\approx$ $10^{-6} \mathrm{M}$ ), most of the micelles contain $\geq 2$ molecules of BChl $a$. If distributed at random in the Stern layer of the spherical micelle, the pigments in doubly-occupied micelles will be separated by as much as 20-30 $\AA$ from each other (the micelle diameter is $\approx 30 \AA$ for the 14 carbon cetyl residue), in agreement with the spectroscopic data of the $780 \mathrm{~nm}$ absorbing form. The smaller fraction of directly interacting dimers, compared to micellar aggregates in non-ionic detergents (e.g., Triton X-100), is probably due to the larger effect of isolated pigments in reducing electrostatic repulsions. A similar scheme is likely to account for the spectral properties of BChl $a$ in CPC micelles (Fig. 2).

In summary, the presented data indicate that positive charges may strongly shift the $\mathrm{Q}_{y}$ transitions of BChl $a$ dimers but have, at the same time, only small effects on the energy of the monomeric transitions. Nevertheless, they have a profound effect on the oscillator strengths of the individual $\mathrm{Q}_{y}$ and $\mathrm{B}_{y}$ transitions, indicative for negative charge delocalization from the $\mathrm{BChl} a$ molecules, or strong interactions of the $\mathrm{BChl} a$ with the polar head-groups of the detergents.

This work was supported by the Deutsche Forschungsgemeinschaft, Bonn (Project Sche 140/9-2).

\section{References}

1 Sauer, K. (1975) in Bioenergetics of Photosynthesis (Govindjee, ed.), pp. 115-181, Academic Press, New York.

2 Katz, J.J., Norris, J.R., Shipman, R.R., Thurnauer, M.C. and Wasielewski, M.R. (1978) Annu. Rev. Biophys. Bioeng. 7, 393434.

3 Katz, J.J., Shipman, L.L., Cotton, T.M. and Janson, T.R. (1978) in The Porphyrins, Vol. V (Dolphin, D., ed.), pp. 402-458, Academic Press, New York.

4 Worcester, D.L., Michalski, T.J., Tyson, R.L., Bowman, M.K. and Katz, J.J. (1989) Physica B 156, 502-504.

5 Katz, J.J., Bowman, M.K., Michalski, T.J. and Worcester, D.L. (1991) in Chlorophylls (Scheer, H., ed.), pp. 211-236, CRC Press, Boca Raton.

6 Krasnovsky, A.A. and Bystrova, M.I. (1980) Biosystems 12, 181194.

7 Pearlstein, R.M. (1982) in Photosynthesis: Energy Conversion by Plants and Bacteria (Govindjee, ed.), pp. 293-331, Academic Press, New York.

8 Pearlstein, R.M. (1988) in The Photosynthetic Bacterial Reaction Center - Structure and Dynamics (Breton, J. and Verméglio, A., eds.), pp. 331-340, Plenum, New York.
9 Gottstein, J. and Scheer, H. (1983) Proc. Natl. Acad. Sci. USA 80, 2231-2234.

10 Scheer, H., Paulke, B. and Gottstein, J. (1985) in Optical Properties and Structure of Tetrapyrroles (Blauer, G. and Sund, H., eds.), pp. 507-522, Reidel, Dordrecht.

11 Gottstein J. (1990) Der Einfluß von grenzflächenaktiven Substanzen auf die Selbstorganisation von Chlorophyllen und Phycocyaninen, Dissertation, Universität München.

12 Schmidt, A., Gottstein, J., Scheer, H. and Scherz, A. (1990) Z. Naturforsch. C 45, 729-732.

13 Scherz, A. and Rosenbach-Belkin, V. (1989) Proc. Natl. Acad. Sci. USA 86, 1505-1509.

14 Scherz, A., Rosenbach-Belkin, V. and Fisher, J.R.E. (1991) in Chlorophylls (Scheer, H., ed.), pp. 237-268, CRC Press, Boca Raton.

15 Scherz, A. and Parson, W.W. (1984) Biochim. Biophys. Acta 766, 653-665.

16 Scherz, A. and Rosenbach-Belkin, V. (1988) in The Photosynthetic Bacterial Reaction Center - Structure and Dynamics (Breton, J. and Verméglio, A., eds.), pp. 295-308. Plenum, New York.

17 Scherer, P.O.J and Fischer, S. (1991) in Chlorophylls (Scheer, H., ed.), pp. 1079-1096, CRC Press, Boca Raton.

18 Abraham, R.J. and Rowan, A.E. (1991) in Chlorophylls (Scheer, H., ed.), pp. 797-834, CRC Press, Boca Raton.

19 Michel, H. and Deisenhofer, J. (1988) Biochemistry 27, 1-7.

20 Deisenhofer, J. and Michel, H. (1989) EMBO J. 8, 2149-2170.

21 Michel, H., Epp, O. and Deisenhofer, J. (1986) EMBO J. 24452451.

22 Allen, J.P., Feher, G., Yeates, T.O., Komiya, H. and Rees, D.C. (1987) Proc. Natl. Acad. Sci. USA 84, 5730-5734.

23 Allen, J.P., Feher, G., Yeates, T.O., Rees, D.C., Deisenhofer, J., Michel, H. and Huber, R. (1986) Proc. Natl. Acad. Sci. USA 83, 8589-8593.

24 Chang, C.H., El-Kabbani, O., Tiede, D., Norris, J. and Schiffer, M. (1991) Biochemistry 30, 5352-5360.

25 El-Kabbani, O., Chang, C.H. Tiede, D., Norris, J. and Schiffer, M. (1991) Biochemistry 30, 5361-5369.

26 Chang, C.H., Tiede, D., Tang, J., Smith, U., Norris, J. and Schiffer, M. (1986) FEBS Lett. 205, 82-86.

27 Eccles, J. and Honig, B. (1983) Proc. Natl. Acad. Sci. USA 80, 4959-4962.

28 Hanson, L.K. (1991) in Chlorophylls (Scheer, H., ed.), pp. 9931014, CRC Press, Boca Raton.

29 Davis, R.C., Ditson, S.C., Fentiman, A.F. and Pearlstein, R.M. (1981) J. Am. Chem. Soc. 103, 6823-6826.

30 Fajer, J., Barkigia, K.M., Smith, K.M., Zhong, E., GudowskaNowak, E. and Newton, M.D. (1990) in Reaction Centers of Photosynthetic Bacteria (Michel-Beyerle, M.E., ed.), pp. 367-376, Springer, Berlin.

31 Bylina, E.J. and Youvan, D.C. (1991) in Chlorophylls (Scheer, H., ed.), pp. 705-722, CRC Press, Boca Raton.

32 Evans, T.A. and Katz, J.J. (1975) Biochim. Biophys. Acta 396, 414-426.

33 Cogdell, R.J. (1986) in Photosynthesis III - Photosynthetic Membranes and Light Harvesting Systems (Staehelin, L.A. and Arntzen, C.J., eds.), pp. 252-259, Springer, Berlin.

34 Zuber, H. and Brunisholz, R.A. (1991) in Chlorophylls (Scheer, H., ed.), pp. 627-704, CRC Press, Boca Raton.

35 VanGrondelle, R., Bergström, H., Sundström, V., Van Dorssen, R.J., Vos, M. and Hunter, C.N. (1988) in Photosynthetic Light Harvesting Systems (Scheer, H. and Schneider, S., eds.), pp. 519-531, De Gruyter, Berlin.

36 Hawthornthwaite, A.M. and Cogdell, R.J. (1991) in Chlorophylls (Scheer, H., ed.), pp. 493-528, CRC Press, Boca Raton.

37 Droupadi, P.R. and V. Krishnan (1985) J. Phys. Chem., 89 909-917. 